\title{
BOUNDARY INTEGRAL METHODS FOR WEDGE DIFFRACTION PROBLEMS: THE ANGLE $2 \pi / n$, DIRICHLET AND NEUMANN CONDITIONS
}

\author{
T. EhrhardT, A. P. NOlasco AND F.-O. SPECK
}

\begin{abstract}
In this paper we use analytical methods for boundary integral operators (more precisely, pseudodifferential operators) together with symmetry arguments in order to treat harmonic wave diffraction problems in which the field does not depend on the third variable and the wave incidence is perpendicular. These problems are formulated as two-dimensional, mixed elliptic boundary value problems in a non-rectangular wedge.

We solve explicitly a number of reference problems for the Helmholtz equation regarding particular wedge angles, boundary conditions, and space settings, which can be modified and generalized in various ways. The solution of these problems in Sobolev spaces was open for some fifty years.
\end{abstract}

Mathematics subject classification (2010): Primary 35J05, 78A45; Secondary 45E10, 47B35.

Keywords and phrases: Wedge diffraction problem, Helmholtz equation, boundary value problem, half-line potential, pseudodifferential operator, Sommerfeld potential, Rawlins factorization.

\section{REFERENCES}

[1] A.-S. Bonnet-Bendhia And A. TILlequin, A limiting absorption principle for scattering problems with unbounded obstacles, Math. Meth. Appl. Sci., 24 (2001), 1089-1111.

[2] L.P. CASTRO AND D. KAPANADZE, Exterior wedge diffraction problems with Dirichlet, Neumann and impedance boundary conditions, Acta Appl. Math. 110 (2010), 289-311.

[3] L.P. CASTRo, F.-O. SPECK And F.S. TeiXeira, On a class of wedge diffraction problems posted by Erhard Meister, Oper. Theory: Adv. Appl., 147 (2004), 211-238.

[4] L.P. CASTRO, F.-O. SPECK AND F.S. TEIXEIRA, Mixed boundary value problems for the Helmholtz equation in a quadrant, Integr. Equ. Oper. Theory, 56 (2006), 1-44.

[5] M. Costabel AND E. STEPHAN, A direct boundary integral equation method for transmission problems, J. Math. Anal. Appl., 106 (1985), 367-413.

[6] T. EHRHARDT, Invertibility theory for Toeplitz plus Hankel operators and singular integral operators with flip, J. Funct. Anal., 208 (2004), 64-106.

[7] T. EhrhaRdT AND F.-O. SPECK, Transformation techniques towards the factorization of nonrational $2 \times 2$ matrix functions, Linear Algebra Appl., 353 (2002), 53-90.

[8] G.I. Èskin, Boundary Value Problems for Elliptic Pseudodifferential Equations, Translations of Mathematical Monographs, 52, AMS, Providence, R. I., 1981.

[9] P. GRIS VARD, Elliptic Problems in Nonsmooth Domains, Monographs and Studies in Mathematics 24, Pitman (Advanced Publishing Program), Boston, 1985.

[10] A.E. HeIns, The Sommerfeld half-plane problem revisited. II. The factoring of a matrix of analytic functions, Math. Meth. Appl. Sci., 5 (1983), 14-21.

[11] G.C. Hsiao AND W.L. Wendland, Boundary Integral Equations, Applied Mathematical Sciences, 164, Springer-Verlag, Berlin 2008.

[12] D. Kapanadze And B.-W. Schulze, Crack Theory and Edge Singularities, Kluwer Academic Publishers, Dordrecht, 2003. 
[13] A.I. KOMECH, Elliptic boundary value problems on manifolds with a piecewise smooth boundary, Math. USSR Sbornik, 21 (1973), 91-135.

[14] A.I. Komech, N.J. Mauser And A.E. Merzon, On Sommerfeld representation and uniqueness in scattering by wedges, Math. Meth. Appl. Sci., 28 (2005), 147-183.

[15] V.A. Kozlov, V.G. Maz'ya And J. Rossmann, Spectral Problems Associated with Corner Singularities of Solutions to Elliptic Equations, Math. Surveys and Monographs, 85, AMS, Providence, R.I. 2001.

[16] G.S. Litvinchuk And I.M. Spitkovsky, Factorization of measurable matrix functions, Oper. Theory: Adv. Appl., 25, Birkhäuser, Basel, 1987.

[17] G.D. Malujinetz, Excitation, reflection and emission of the surface waves on a wedge with given impedences of the sides, Dokl. Acad. Nauk SSSR, 121 (1958), 436-439.

[18] E. MeIster, Some multiple-part Wiener-Hopf problems in Mathematical Physics, in: Mathematical Models and Methods in Mechanics, Banach Center Publications, 15, PWN - Polish Scientific Publishers, Warsaw, 1985, 359-407.

[19] E. MEISTER, Some solved and unsolved canonical problems of diffraction theory, Lecture Notes in Math., 1285, Springer, Berlin 1987, 320-336.

[20] E. Meister, F. Penzel, F.-O. Speck And F.S. TeIXeIRA, Some interior and exterior boundaryvalue problems for the Helmholtz equation in a quadrant, Proc. Roy. Soc. Edinburgh, Sect. A, 123 (1993), 275-294.

[21] E. MeISTER AND F.-O. Speck, Some multidimensional Wiener-Hopf equations with applications, Trends in Applications of Pure Mathematics to Mechanics, Vol. II, Monographs Stud. Math., 5, Pitman, London 1979, 217-262.

[22] E. MEISTER AND F.-O. SPECK, A contribution to the quarter-plane problem in diffraction theory, J. Math. Anal. Appl., 130 (1988), 223-236.

[23] E. Meister And F.-O. SPECK, Modern Wiener-Hopf methods in diffraction theory, Pitman Res. Notes Math. Ser., 216 (1989), 130-171.

[24] S.G. Mikhlin And S. Prössdorf, Singular Integral Operators, Springer-Verlag, Berlin, 1986.

[25] A. Moura Santos, F.-O. Speck And F.S. TeixeIra, Minimal normalization of Wiener-Hopf operators in spaces of Bessel potentials, J. Math. Anal. Appl., 225 (1998), 501-531.

[26] B. NoBLE, Methods Based on the Wiener-Hopf Technique, International Series of Monographs on Pure and Appl. Math., Vol. 7, London 1958.

[27] A.D. Rawlins, The explicit Wiener-Hopf factorization of a special matrix, Z. Angew. Math. Mech., 61 (1981), 527-528.

[28] A.D. RAWLins, The solution of a mixed boundary value problem in the theory of diffraction, J. Eng. Math., 18 (1984), 37-62.

[29] A.D. Rawlins, Plane-wave diffraction by a rational wedge, Proc. Roy. Soc. London, Ser. A, 411 (1987), 265-283.

[30] A.F. DOS SAnTOS AND F.S. TEIXEIRA, The Sommerfeld problem revisited: solution spaces and the edge conditions, J. Math. Anal. Appl., 143, (1989), 341-357.

[31] F.-O. SPECK, Mixed boundary value problems of the type of Sommerfeld's half-plane problem, Proc. Roy. Soc. Edinburgh, Sect. A, 104 (1986), 261-277.

[32] F.-O. SPECK, Sommerfeld diffraction problems with first and second kind boundary conditions, SIAM J. Math. Anal., 20 (1989), 396-407.

[33] F.-O. SPECK AND E.P. StePhAn, Boundary value problems for the Helmholtz equation in an octant, Integr. Equ. Oper. Theory, 62 (2008), 269-300.

[34] E.M. Stein, Singular Integrals and Differentiability Properties of Functions, Princeton University Press, Princeton, N.J., 1970.

[35] H. Triebel, Theory of Function Spaces. II., Monographs in Mathematics, 84. Birkhäuser, Basel, 1992.

[36] P.Ya. Ufimtsev, Theory of Edge Diffraction in Electromagnetics, Tech Science Press, Encino, California, 2003.

[37] V.B. VASIL'Ev, Wave Factorization of Elliptic Symbols: Theory and Applications, Kluwer Academic Publishers, Dordrecht, 2000.

[38] W.L. Wendland, E. Stephan and G.C. Hsiao, On the integral equation method for the plane mixed boundary value problem of the Laplacian, Math. Methods Appl. Sci., 1 (1979), 265-321. 
[39] P. Zhevandrov And A. Merzon, On the Neumann problem for the Helmholtz equation in a plane angle, Math. Meth. Appl. Sci., 23 (2000), 1401-1446. 